\title{
LABORATORIO DE INVESTIGACIÓN - CREACIÓN: LA AUTOPUBLICACIÓN COMO PRÁCTICA ARTÍSTICA CONTEMPORÁNEA ENMARCADA BAJO EL ESTUDIO DE LA MOVILIDAD HUMANA
}

Research laboratory - creation: Self-publishing as a contemporary artistic practice framed under the study of human mobility

\author{
Viviana Aguillón García \\ Docente Coordinadora Semillero SINAV \\ Viviana.aguillon@unad.edu.co \\ Alejandra Correa Giraldo \\ Semillarista \\ aleja.25correa@gmail.com \\ Natalia del Socorro Álvarez Calao \\ Semillarista \\ nataliacalao@gmail.com \\ Erick Marín \\ Docente Co-investigador \\ erick.marin@unad.edu.co \\ Nashly Pérez \\ Docente Co-investigadora \\ nashly.perez@unad.edu.co
}

Universidad Nacional Abierta y a Distancia

Programa de Artes Visuales

Colombia 


\section{RESUMEN}

El trabajo de investigación propone la realización de un laboratorio de formación complementaria al Programa de Artes Visuales, donde se explorarán los medios de autopublicación como herramientas de creación transdisciplinar y de difusión de obra en el contexto contemporáneo.

La base conceptual y teórica del proyecto gira en torno a la movilidad humana, un tema transversal que permite discutir, reflexionar y aportar una mirada crítica sobre los aspectos locales que ésta implica, incluidas las dimensiones corporales y espacio-geográficas, hasta sus configuraciones simbólicas relacionadas con la noción de lo diverso y las representaciones estéticas derivadas de esta noción.

Durante la ejecución de este proyecto, se proponen cuatro fases de desarrollo vinculadas a la estrategia de investigación-creación: En la primera fase se desarrollará un proceso de fundamentación teórica. En la segunda fase se propone una serie de talleres participativos y colaborativos que involucran a los estudiantes vinculados al semillero de investigación SINAV y sus comunidades ubicadas en territorios específicos del país. La tercera fase comprende el acompañamiento al desarrollo de los procesos de investigación-creación de los participantes del laboratorio. Finalmente, en la fase cuatro se propone una estrategia de exhibición: Una exposición de libro digital alojado en el Museo Universitario de Artes Digitales MUNAD ${ }^{1}$ de la Universidad Nacional Abierta y a Distancia, que recopile el desarrollo del laboratorio y las piezas finales derivadas del proceso y una exposición museográfica que exponga las piezas físicas producidas por los estudiantes y las experiencias desarrolladas colectivamente en los talleres participativos

\section{PALABRAS CLAVE:}

Autopublicación, movilidad humana, artes visuales, laboratorio, arte contemporáneo, migración

Información básica del proyecto:

- Tipo de Proyecto: semillero de investigación.

- Nombre del semillero: Semillero de Investigación en Artes Visuales SINAV. https://spark.adobe.com/page/IMLUF4riA6zG8/

- Nombre de la universidad o institución de educación superior: Universidad Nacional Abierta y a Distancia, UNAD.

- Título del proyecto: Laboratorio de investigación - creación: la autopublicación como práctica artística contemporánea enmarcada bajo el estudio de la movilidad humana.

- Nombre y datos de contacto de los ponentes (máximo dos por proyecto). Alejandra Correa - Natalia Calao

- Nombre y contacto del docente asesor del semillero (si aplica). Viviana Aguillón García

- Modalidad de Participación: proyecto en curso

- Área: arte, arquitectura \& diseño

- Subárea del conocimiento: artes visuales \& digitales

\footnotetext{
${ }^{1}$ En el siguiente enlace puede visitar el Museo Universitario de Artes Digitales MUNAD https://munad.unad.edu.co/ ENCUENTRO CON SEMILLEROS, APORTES Y REFLEXIONES

Volumen 2 No 2 (2020) | ISSN 2711-4414
} 
INTRODUCCIÓN

La construcción de imagen a partir de la movilidad humana como fenómeno actual, epistémico y político constituye el núcleo temático del presente proyecto; dicho fenómeno, junto a todas las variables que conlleva, como la constante transformación del espacio, los vínculos sociales generados entre territorios, la gestación de identidades y formas de vida sincréticas, por nombrar solo algunas, serán abordadas mediante la articulación entre estudiantes, comunidad y docentes, en productos comprendidos dentro de la categoría de publicaciones artísticas autogestionadas (libros de artista, fanzines, fotozines, artzine, fotolibros), y posteriormente compendiados en una maleta museal que recoja el proceso en la vía de lo metodológico y de lo conceptual, materializado en productos que serán recogidos en una exposición de libro digital alojado en el Museo Universitario de Artes Digitales MUNAD.

Para el desarrollo de este laboratorio de investigación-creación, entenderemos la movilidad humana como el conjunto de desplazamientos voluntarios entre espacios entendidos como territorios que evocan los significados que provienen y les dan sentido a nuestras vivencias, recuerdos y las tensiones propias del contacto con los otros; paralelamente, este concepto no excluye aquellos desplazamientos forzados que también generan dinámicas y resemantizaciones de las dimensiones espacio-geográficas.

Cada publicación de arte impreso es una plataforma de experimentación con rutas, secuencias, colecciones de imágenes, fragmentos de espacio y narrativas desde y hacia múltiples voces. Esta estrategia fundamenta las expresiones y uso de la movilidad humana como concepto de creación y en concordancia con este planteamiento temático, la propuesta de difusión de las piezas artísticas resultantes del laboratorio será una maleta-museo como símbolo de viaje y tránsito de un destino a otro. La maleta viajará a distintos centros de nuestra Universidad y fuera de ella con el apoyo de nuestros aliados. Así mismo, esta exposición tendrá su réplica virtual, alimentando el Museo Universitario de Artes Digitales, MUNAD.

\section{MÉTODO}

\section{Fase 1: Fundamentación}

- Durante la primera fase del proyecto se realizará una serie de talleres y teleconferencias que conectan no solo los agentes involucrados en el proceso creativo, sino toda la red comunitaria y educativa que interceda en la investigación. Dichos encuentros constituyen un documento de socialización sobre el núcleo temático -la movilidad humana- y sobre la producción editorial de autopublicación como herramienta de difusión de las experiencias y saberes resultantes del proceso.

\section{Fase 2: Acompañamiento a procesos}

Posterior a los talleres de cocreación transmitidos desde las ciudades de Bogotá, Cali y Dosquebradas, se elegirán diez procesos de estudiantes vinculados de manera oficial al proyecto, que serán visionados y asesorados por los docentes que acompañan el semillero y publicados de acuerdo con el eje conceptual y técnico del laboratorio.

\section{Fase 3: Circulación y Exhibición}


Como fase final del proyecto, los resultados estarán reunidos en la Maleta Museal, que recogerá las memorias del proceso de creación logrado durante el desarrollo proyecto, al tiempo que contendrá los productos realizados por los estudiantes y las personas que hicieron parte de los talleres participativos. Se construirá también un libro digital que estará alojado en el Museo Universitario de Artes Digitales, MUNAD, que recopile el desarrollo del laboratorio y las piezas finales derivadas del proceso junto a una exposición museográfica que exponga las piezas físicas producidas por los estudiantes.

\section{Estrategias de circulación:}

Dentro de las estrategias contempladas para la circulación del proyecto se planean las siguientes acciones:

1. Serie talleres y videoconferencias dirigidas por especialistas en los temas vinculados al proyecto y alojadas en el Centro de Documentación “Taller Virtual”, del programa de Artes Visuales.

2. Alianzas nacionales: el proyecto cuenta con aliados estratégicos que aportarán un mayor alcance en la difusión y circulación de los procesos dentro del laboratorio, el grupo de Investigación de Movilidad Humana en Dosquebradas, y artistas y colectivos vinculados con los procesos de autopublicación a nivel nacional.

3. Con el apoyo de la Red de Comunicación del programa de Artes Visuales de la UNAD, se divulgarán los eventos y avances concernientes a cada fase, así como se pretende dar visibilidad a los procesos y resultados del laboratorio mediante encuentros interinstitucionales.

\section{RESULTADOS PRELIMINARES}

Durante la fase de fundamentación de nuestro proyecto hemos tenido la posibilidad de concretar espacios de discusión y reflexión sobre la relación entre el arte y la migración en colaboración con docentes investigadores de áreas vinculadas a las ciencias sociales, otorgando una perspectiva interdisciplinaria a la formación de los estudiantes semillaristas vinculados al proyecto, así como hemos desarrollado talleres que proponen un análisis frente a la imagen fotográfica como medio de expresión contemporánea y una reflexión frente las prácticas de autoedición y autopublicación como herramientas de difusión y exhibición efectiva de los procesos de creación individuales y colectivos.

A continuación, exponemos algunos avances de este proceso:

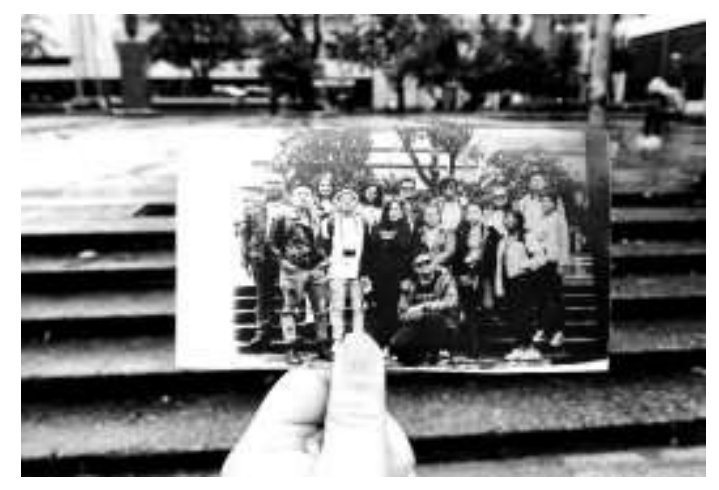

Taller de Deriva Fotográfica. Bogotá

Programa Artes Visuales UNAD - Programa Comunicación Social UNAD

Dirigido por la docente Viviana Aguillón, líder del proyecto. 

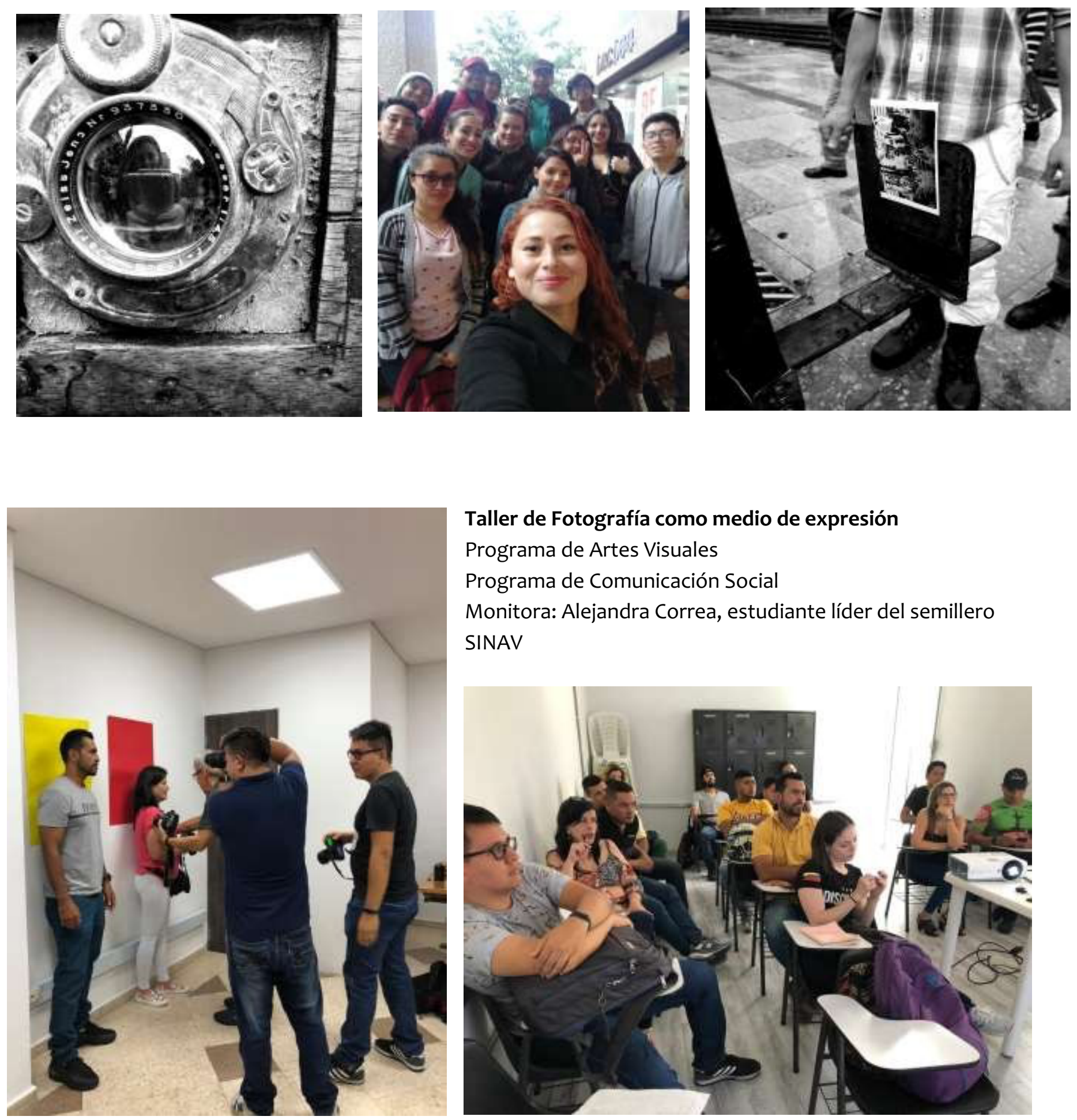

Taller de Fotografía como medio de expresión

Programa de Artes Visuales

Programa de Comunicación Social

Monitora: Alejandra Correa, estudiante líder del semillero SINAV

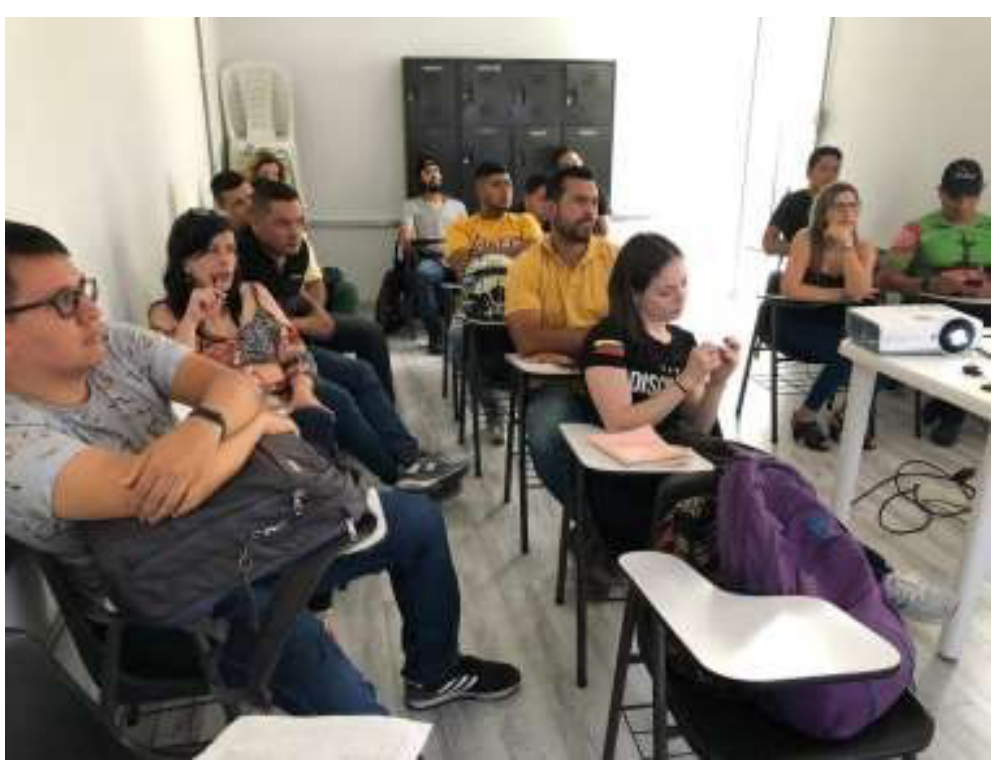


Aguillón, Correa, Álvarez, Marín \& Pérez
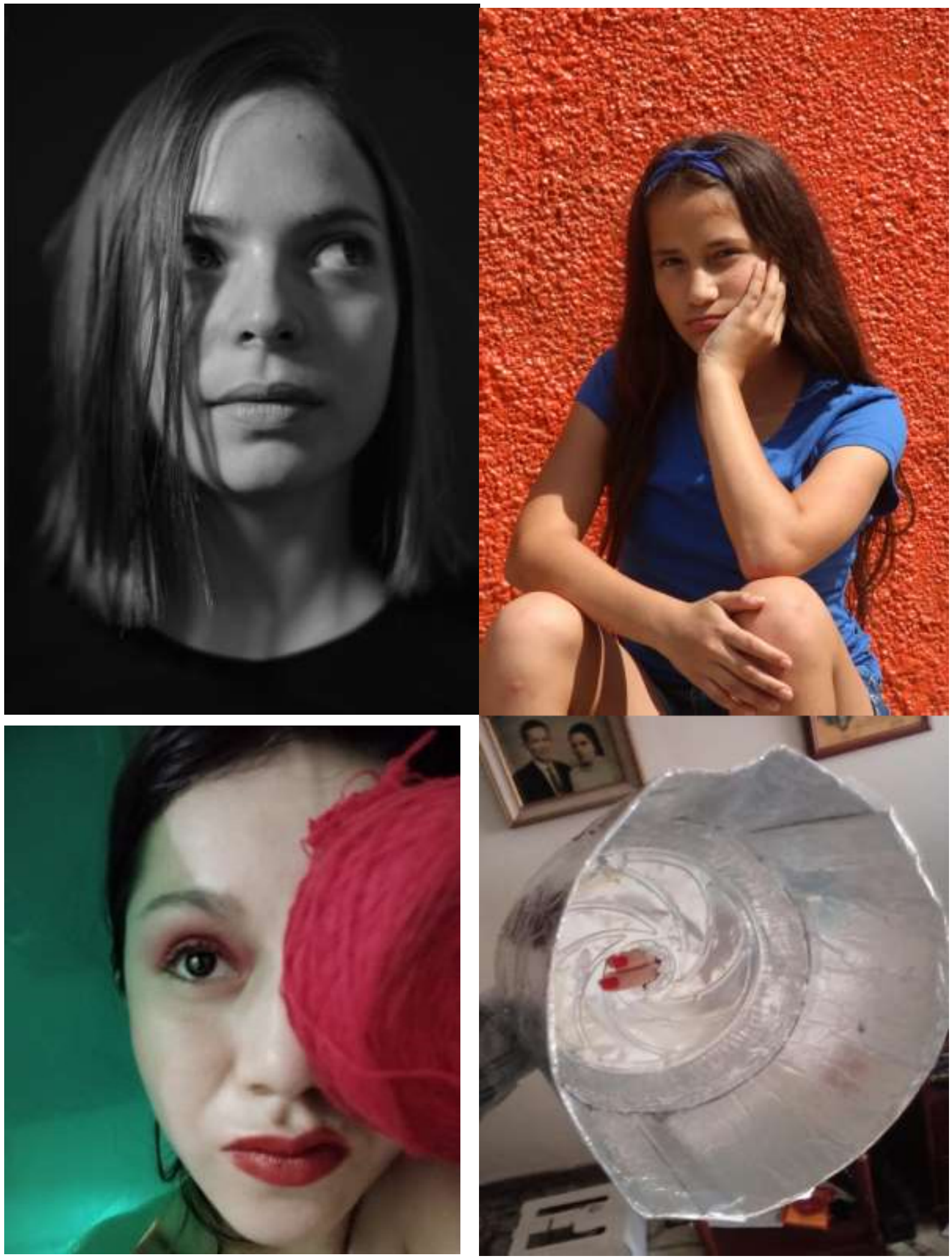

ENCUENTRO CON SEMILLEROS, APORTES Y REFLEXIONES

Volumen 2 No 2 (2020) | ISSN 2711-4414 


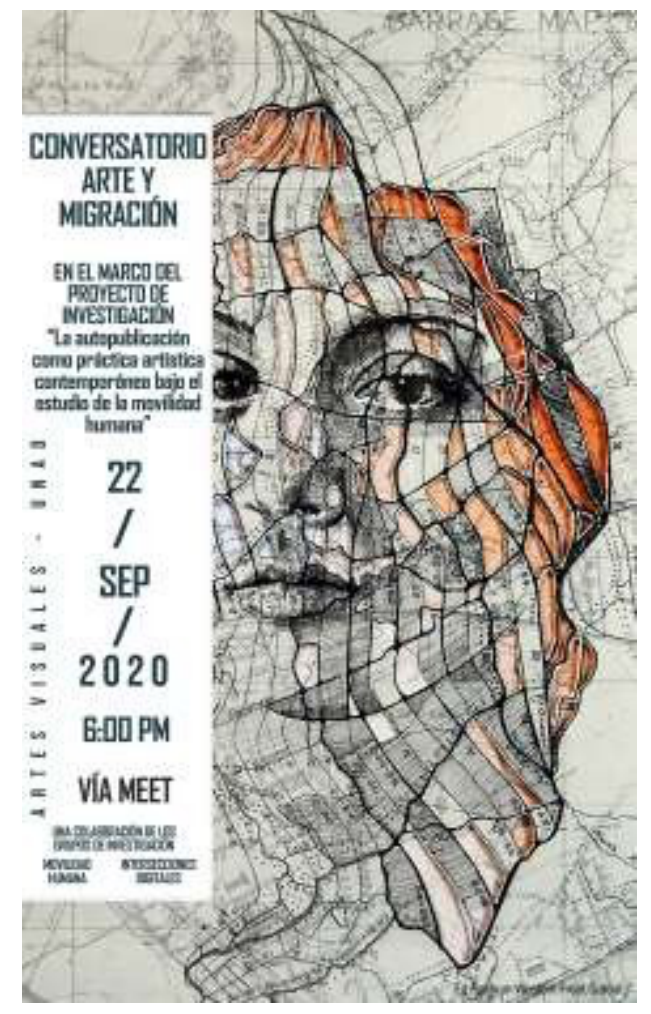

\section{Conversatorio Arte y Migración}

Colaboración entre el Grupo de Investigación Movilidad Humana e Intersecciones Digitales (SINAV).

Moderado por el Maestro Erick Marín, co-investigador del proyecto con la participación de William Mejía Ochoa, Economista de la Universidad Libre, con especialización en Política Económica de la Universidad de Antioquia y Maestría en Migraciones Internacionales de la Universidad Tecnológica de Pereira. Con experiencia en investigaciones y consultorías nacionales e internacionales en el campo de la migración.

Vanessa Quintero Ríos, Politóloga de la Universidad Nacional, sede Medellín, magíster en Migraciones Internacionales de la Universidad Tecnológica de Pereira y estudiante del Doctorado en Diversidad de la Universidad de Manizales. Miembro del grupo de Investigación en Movilidad Humana y experiencia investigativa en el campo.

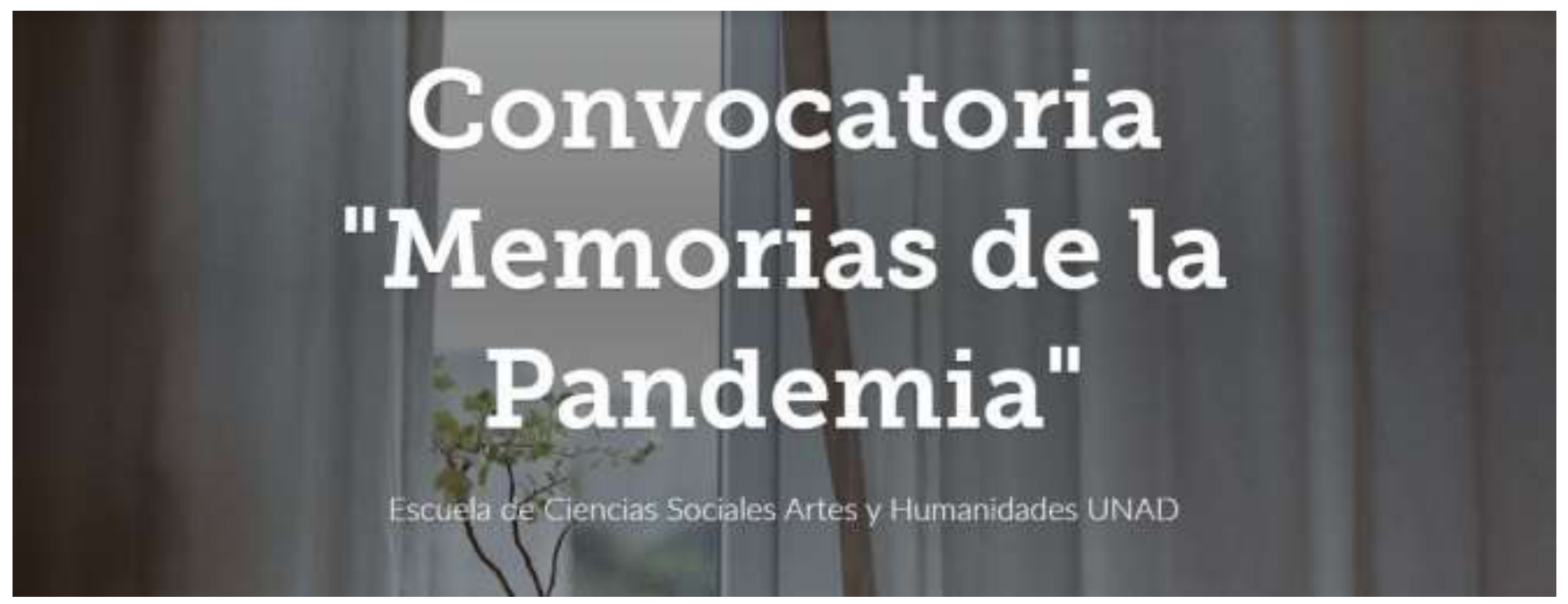

Enlace de la convocatoria: https://spark.adobe.com/page/QrErYVQFB5GEK/ 


\section{Aguillón, Correa, Álvarez, Marín \& Pérez}

La Convocatoria "Memorias de la Pandemia" busca visibilizar las prácticas cotidianas en el confinamiento, generando propuestas de creación que permitan el encuentro a la distancia, promoviendo así la reflexión conjunta frente a la crisis y la construcción de sociedad en confinamiento. De este modo, se invita a la reflexión crítica que nos permita comprender la manera en que nos relacionamos con el otro, a repensar el modelo económico en el cual estamos insertos, la manera en que habitamos el mundo y a los modos en que construimos comunidad. Estas son algunas de las propuestas fotográficas seleccionadas.
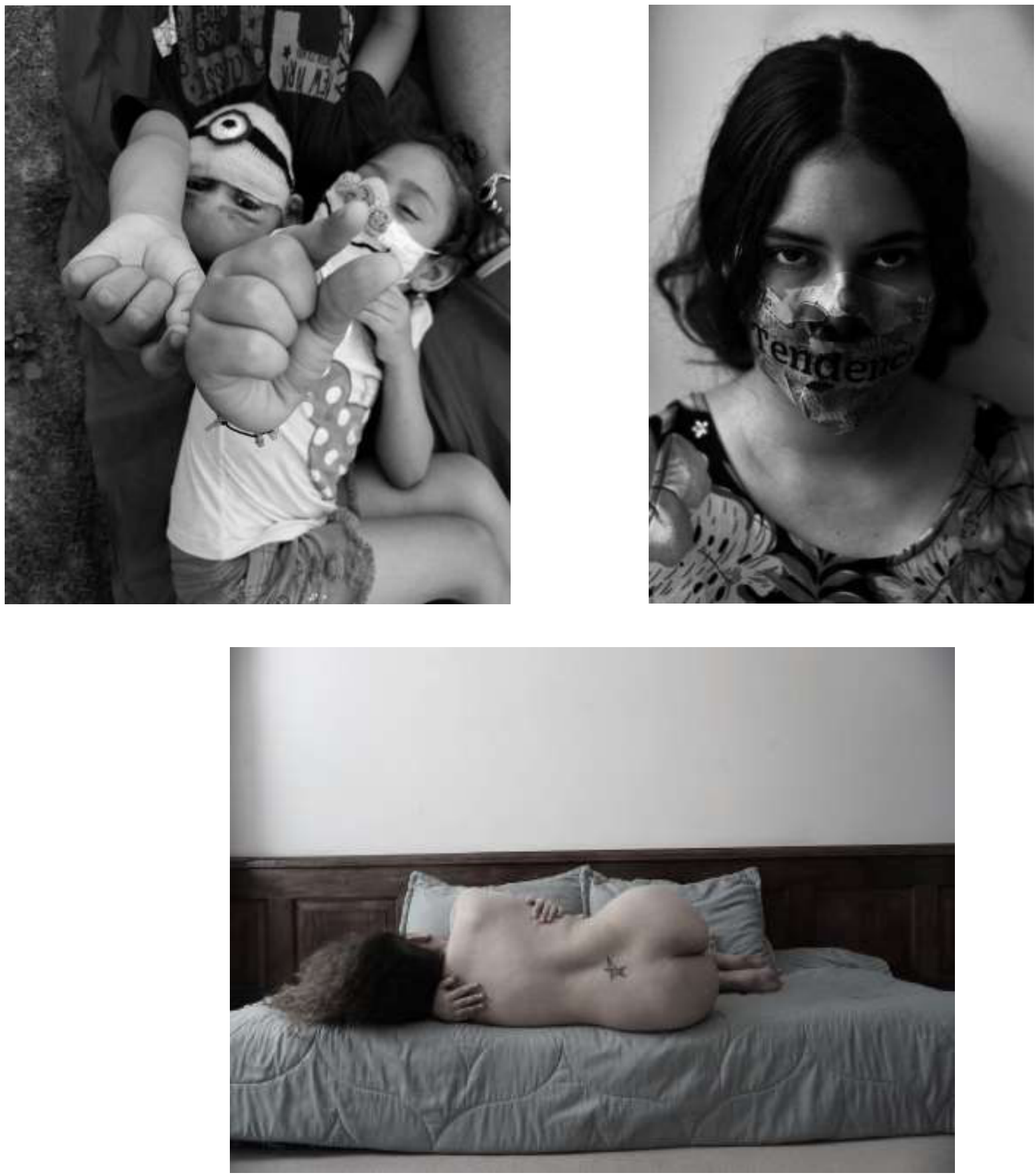
Aguillón, Correa, Álvarez, Marín \& Pérez
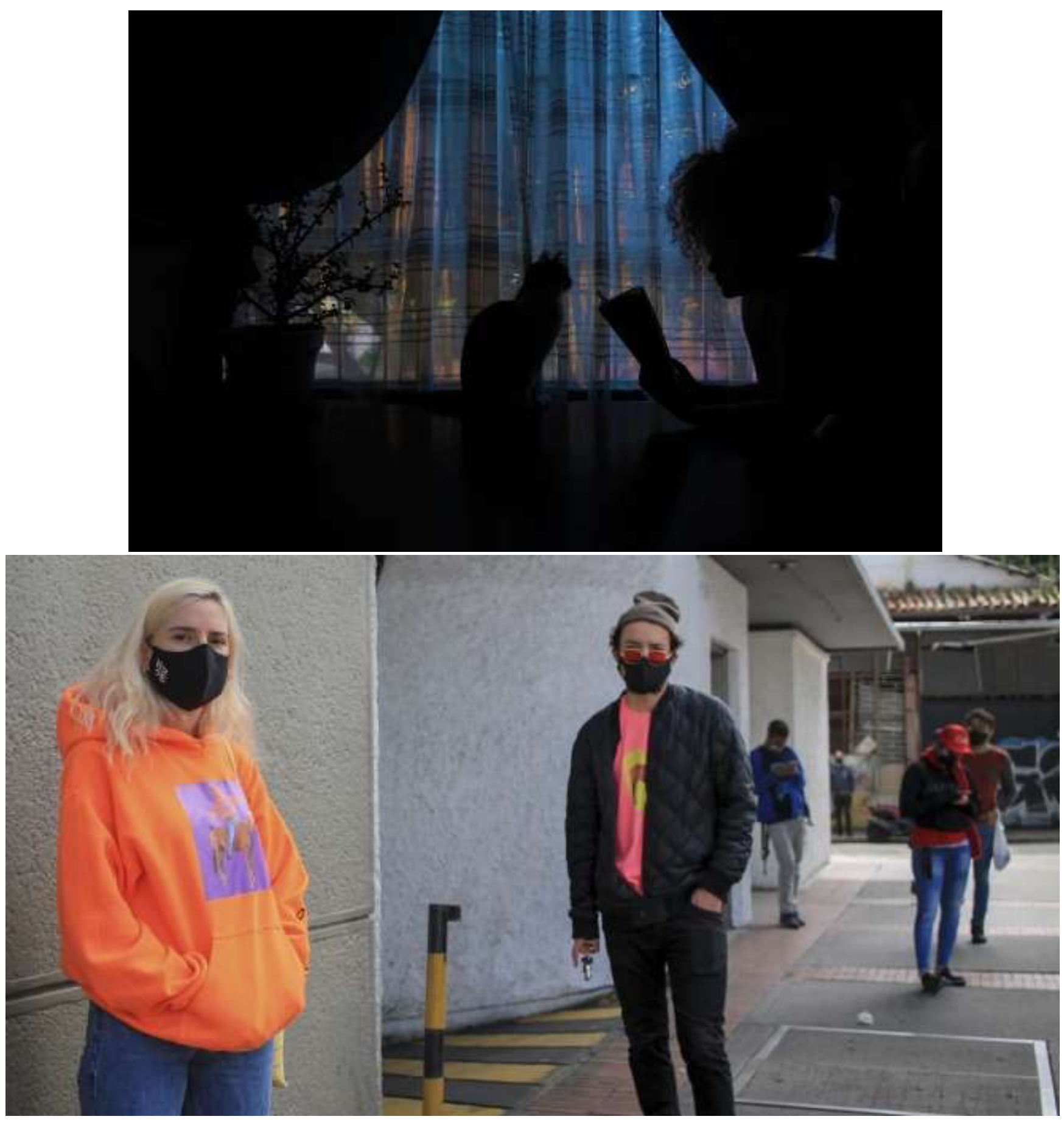

ENCUENTRO CON SEMILLEROS, APORTES Y REFLEXIONES

Volumen 2 No 2 (2020) | ISSN 2711-4414 


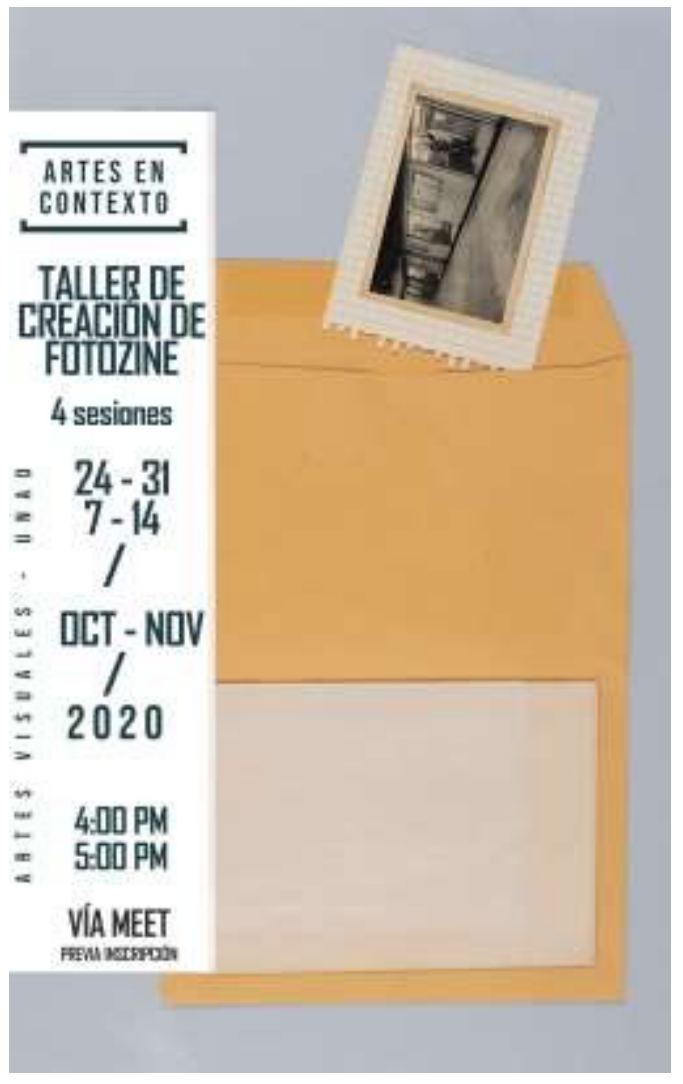

\section{Taller de creación de fotozine}

Dirigido por Viviana Aguillón, investigadora del proyecto.

El taller está abierto para la comunidad académica y público general, sin embargo, derivado de este proceso, se propone realizar un visionado de las propuestas preliminares para publicación y circulación en la Maleta Museal.

\section{DISCUSIÓN Y CONCLUSIONES}

Se apropia la coyuntura global del confinamiento como escenario metodológico para proponer procesos de creación donde se visibiliza la pertinencia y el sentido de la autopublicación como medio de expresión, circulación y exhibición en el arte actual.

\section{REFERENCIAS BIBLIOGRÁFICAS}

Bergson, H. (1977). Memoria y vida. Textos escogidos por Gilles Deleuze. Madrid: Alianza Editorial

Crespo, B. (2012). El libro-arte / libro de artista: tipologías secuenciales, narrativas y estructuras. Anales de Documentación, 15(1). http://dx.doi.org/10.6018/analesdoc.15.1.125591.

Daza-Orozco, CE. (2019) La configuración de los espacios como elementos de la reflexión gráfica. Bogotá: Fundación Universitaria San Mateo.

Daza-Orozco, CE. (2018). Narrativas visuales: perspectivas y análisis desde Iberoamérica. Bogotá. Fundación Universitaria San Mateo 


\section{Aguillón, Correa, Álvarez, Marín \& Pérez}

Delgado, M. (1999). El animal público. Hacia una antropología de los espacios urbanos. España: Editorial Anagrama.

Debord, G. (1958). Teoría de la deriva. Texto aparecido en el \# 2 de Internationale Situationniste. Madrid.

$\begin{array}{llll}\text { Literatura } & \text { Gris. } & \text { (1999). } & \text { Recuperado }\end{array}$ https://www.ugr.es/ silvia/documentos\%20colgados/IDEA/teoria\%20de\%20la\%20deriva.pdf

Joseph, I. (1988). El transeúnte y el espacio urbano. Barcelona: Editorial Gedisa

Lindón, A. (2002). La construcción social del territorio y los modos de vida en la periferia metropolitana. Territorios, (7), 27-41. Recuperado de http://www.redalyc.org/articulo.oa?id=35700703

Macaya-Ruiz, A. (2017) Trayectos en el mapa: artes visuales como representación del conocimiento. Arte, Individuo y Sociedad, 29(2), 387-404.

Mínguez, H. (2018). Resistirse al tiempo: los libros-arte y el cultivo de la memoria. Arte, Individuo y Sociedad, 30(3), 519-540.

Organización Internacional para las Migraciones. (2006). Derecho Internacional sobre Migración. Glosario Sobre Migración. Suiza.

Rubio, R. (2001). Redes sociales y mecanismos de apoyo en la migración de mexicanos a Estados Unidos: datos de una encuesta de flujos. Comunicación presentada al VI Congreso de la ADEH, Castelo Branco, Centre d'EstudisDemog 